\title{
Temporal Resolution and Active Auditory Discrimination Skill in Vocal Musicians
}

\author{
Prawin Kumar $^{1}$ Himanshu Kumar Sanju ${ }^{1} \quad$ J. Nikhil ${ }^{1}$ \\ ${ }^{1}$ Department of Audiology, All India Institute of Speech and Hearing, \\ Mysore, Karnataka, India \\ Address for correspondence Himanshu Kumar Sanju, Post Graduate in \\ Audiology, Department of Audiology, AllSH, Manasagangothri, Mysore, \\ Int Arch Otorhinolaryngol 2016;20:310-314. \\ Karnataka, India 570006 (e-mail: himanshusanjuaiish@gmail.com).
}

\begin{abstract}
Introduction Enhanced auditory perception in musicians is likely to result from auditory perceptual learning during several years of training and practice. Many studies have focused on biological processing of auditory stimuli among musicians. However, there is a lack of literature on temporal resolution and active auditory discrimination skills in vocal musicians.

Objective The aim of the present study is to assess temporal resolution and active auditory discrimination skill in vocal musicians.

Method The study participants included 15 vocal musicians with a minimum professional experience of 5 years of music exposure, within the age range of 20 to 30 years old, as the experimental group, while 15 age-matched non-musicians served as the control group. We used duration discrimination using pure-tones, pulse-train duration discrimination, and gap detection threshold tasks to assess temporal processing skills in both groups. Similarly, we assessed active auditory discrimination skill in both groups using Differential Limen of Frequency (DLF). All tasks were done using MATLab software installed in a personal computer at 40dBSL with maximum likelihood procedure. The collected data were analyzed using SPSS (version 17.0).

Result Descriptive statistics showed better threshold for vocal musicians compared with non-musicians for all tasks. Further, independent $t$-test showed that vocal

Keywords

- singing

- auditory stimulation

- temporal auditory area musicians performed significantly better compared with non-musicians on duration discrimination using pure tone, pulse train duration discrimination, gap detection threshold, and differential limen of frequency.

Conclusion The present study showed enhanced temporal resolution ability and better (lower) active discrimination threshold in vocal musicians in comparison to non-musicians.
\end{abstract}

\section{Introduction}

Auditory temporal processing is defined as perception of sound or alternation of sound within a restricted time duration. ${ }^{1}$ Temporal resolution ability allows us to detect small and sudden change in sound stimuli. Good auditory temporal resolution ability is important for understanding speech in noise in listeners with normal hearing, hearing aid users,

received

July 23, 2015

accepted

October 4, 2015

published online

December 17, 2015 individuals with cochlear implant, and language disorder groups. Temporal processing is a fundamental ability in the perception of both verbal and non-verbal stimuli. ${ }^{2}$ Previous literature also reported the importance of temporal processing in the perception of music, rhythm, periodicity, phoneme discrimination, duration discrimination, and pitch discrimination. ${ }^{3,4}$ According to Parbery et $\mathrm{al}^{5}$, musical training and

Copyright $\odot 2016$ by Thieme Publicações License terms Ltda, Rio de Janeiro, Brazil 
exposure enhances one's ability to code sudden change in stimuli. Music is one of the most demanding cognitive and neural challenges, which requires very precise and accurate timing of many actions, exact interval control of pitch not involved in language, and producing sound in many different ways. Enhanced auditory perception in musicians is likely to result from auditory perceptual learning during several years of training and practice. Moreover, music contains fine modulation of amplitude, frequency, and temporal aspects, which make the musicians experts in identifying such su0062tle fluctuations. In recent literature of plasticity dependent on experience, two studies explained some of the pre-requisites for inducing neuroplasticity, which include complexity, intensity, and repetition of training. ${ }^{6,7}$ Another voxel-based morphometric study by Abdul et al showed significantly increased gray matter volume in musicians compared with non-musicians. ${ }^{8}$ Results were positively correlated with years of music experience. ${ }^{8}$ This study also showed the change due to musical training in middle and superior cerebellar peduncle in trained musicians. ${ }^{8}$

Most trained and professional musicians are involved in intensive practice from many years in terms of both intense and repetitive to attain a high level of expertise. In case of vocal singers control of pitch is a complex biomechanical and aerodynamic system. Researchers agree that the musician's ability to produce a precise pitch is very important for the professional vocal musician. Literature also showed that accurate pitch control is mainly dependent on auditory perceptual monitoring, proprioceptive feedback of the laryngeal system and phonatory reflex systems. ${ }^{9-11}$ Professional singers consistently control fundamental frequency and maintain targeted pitch better than non-singers. Thus, there must be a better temporal resolution ability and active auditory discrimination threshold in vocal musicians compared with non-musicians. Many studies have focused on biological processing of auditory stimuli among musicians. ${ }^{12-14}$ However, there is a lack of literature on temporal resolution and active auditory discrimination skills in vocal musicians. The effect of musical training and experience on temporal processing has not been studied using a combination of tasks i.e., duration discrimination using pure tones, pulse train duration discrimination, and gap detection threshold. Hence, the aim of the present study is to assess temporal resolution and active auditory discrimination skill in vocal musicians.

\section{Method}

\section{Participants}

Two groups of subjects (15 experimental and 15 in the control group) within the age range of 20-30 years participated in the study. The subjects with minimum professional experience of 5 years of vocal musical exposure participated in experimental group. Age-matched participants without any formal training of music qualified as non-musicians (control group). All the participants provided informed written consent.

\section{Participant Selection Criteria}

All the participants were having normal hearing thresholds as defined by pure tone thresholds of $<15 \mathrm{dBHL}$ at $250 \mathrm{~Hz}$,
$500 \mathrm{~Hz}, 1000 \mathrm{~Hz}, 2000$ Hz, $4000 \mathrm{~Hz}$, and $8000 \mathrm{~Hz}$. Further, they had normal middle ear functioning, as revealed by the middle ear analyzer. We used click-evoked auditory brainstem response (ABR) to rule out any retrocochlear pathology. Participants who had any other otological, neuromuscular, and neurological problem were excluded from the study based on structured case history.

\section{Testing Environment}

All the behavioral tests were performed in a sound treated room where noise levels were in accordance with the guidelines in ANSI S3.1. The testing rooms were well illuminated and air-conditioned for the comfort of the experimenter as well as of participants.

\section{Procedure}

Pure tone thresholds was obtained using a modified version of Hughson and Westlake procedure across octave frequencies from 250, 500, 1000, 2000, $4000 \mathrm{~Hz}$, and $8000 \mathrm{~Hz}$ for air conduction and frequencies from 500, 1000, 2000, and $4000 \mathrm{~Hz}$ for bone conduction. ${ }^{15}$ We used a middle ear analyzer to carry out tympanometry using a probe tone frequency of $226 \mathrm{~Hz}$ and to obtain ipsilateral and contralateral acoustic reflexes thresholds at $500 \mathrm{~Hz}, 1000 \mathrm{~Hz}, 2000 \mathrm{~Hz}$, and $4000 \mathrm{~Hz}$. We administered duration discrimination using pure tone, pulse train duration discrimination, and gap detection threshold tasks on both groups of participants to assess temporal resolution ability. Similarly, differential limen of frequency tasks were given to both groups of participants to assess active auditory discrimination skill with MATLab software using maximum likelihood procedure technique through a calibrated headphone (Sennheiser Urbanite $\mathrm{XL}$ ) attached to a personal computer. The program provided feedback on the computer screen after every response as to whether it was correct or incorrect. We considered an average of three blocks as threshold. We adopted this procedure to obtain more precise and reliable thresholds.

\section{Duration Discrimination using Pure Tone}

In duration discrimination using pure tone $(1000 \mathrm{~Hz})$, we measured the minimum difference in duration required to perceive the two otherwise identical stimuli, using maximum likelihood procedure. The duration of the standard tone was 250 milliseconds. The duration of the variable tone was changed based on response of the participants. We used two alternative forced choice procedures in which the participants were asked to indicate which tone was longer in duration.

\section{Pulse Train Duration Discrimination}

In pulse train duration discrimination, the standard stimulus consists of six 20 milliseconds pulses of $1 \mathrm{KHz}$ tone. These pulses are arranged in three pairs, with 40 milliseconds of silence between each member of a pair and 120 milliseconds between pairs. The temporal structure of the variable sequence is varied by increasing the separation between members of each pair, with a corresponding decrease in the between-pair time and, thus, a constant interval between 
312 Temporal Resolution and Active Auditory Discrimination in Vocal Musicians Kumar et al.

Table 1 Mean and standard deviation (SD) of duration discrimination using pure tone, pulse train duration discrimination, gap detection threshold, and differential limen of frequency

\begin{tabular}{|l|l|l|l|l|l|l|l|l|}
\hline & \multicolumn{2}{|l|l|l|l|}{$\begin{array}{l}\text { Pure Tone Duration } \\
\text { Discrimination }\end{array}$} & \multicolumn{2}{l|}{$\begin{array}{l}\text { Pulse train duration } \\
\text { discrimination }\end{array}$} & \multicolumn{2}{l|}{$\begin{array}{l}\text { Gap Detection } \\
\text { Threshold }\end{array}$} & \multicolumn{2}{l|}{$\begin{array}{l}\text { Differential Limen } \\
\text { of Frequency }\end{array}$} \\
\hline & Mean & SD & Mean & SD & Mean & SD & Mean & SD \\
\hline Vocal Musicians & 23.13 & 10.16 & 19.30 & 5.29 & 1.81 & 0.39 & 5.86 & 1.64 \\
\hline Non-Musicians & 38.93 & 13.18 & 35.17 & 13.76 & 2.47 & 0.48 & 10.33 & 1.34 \\
\hline
\end{tabular}

Abbreviation: SD, standard deviation.

the first tones in each of the successive pairs. Thus, the first, third, and fifth tones are fixed in time, while the onsets of the second, fourth, and sixth tones are delayed by a varying amount. The parameters that varied adaptively were duration of gap within or between pairs of the variable stimulus to make different rhythm from standard stimuli. The subject task was to identify odd rhythm in a group of two standard and one variable stimuli.

\section{Gap Detection Threshold}

Gap detection threshold was assessed using 750 milliseconds of Gaussian noise with gap in the center. Gap duration was varied according to listener performance using maximum likelihood procedure. The noise had 0.5 milliseconds cosine ramps at the beginning and end of the gap. In the three alternative forced choice task, the reference stimulus was always a 750-millisecond white noise without gap, whereas the variable stimulus contained a gap. We took the minimum gap duration required to perceive a gap in noise as the threshold.

\section{Differential Limen of Frequency}

We assessed differential limens of frequency at $1000 \mathrm{~Hz}$ with the help of MATLab software using the maximum likelihood procedure technique. Three number of blocks were taken for differential limen of frequency. Each block contained 35 trials. We adopted three alternative forced choice procedures for response. The clients were instructed to discriminate highest pitch among three tones (250 milliseconds) presented one after the other.

\section{Statistical Analysis}

We performed descriptive statistics to find out mean and standard deviation (SD) for all tasks in vocal musicians and non-musicians. Independent $t$-test was done to compare between musicians and non-musicians for all task to check any significant difference between groups.

\section{Results}

To analyze the data collected from vocal musicians and nonmusicians, we performed descriptive statistics and independent $t$-test using SPSS (version 17.0). The purpose of descriptive statistics was to find out mean and standard deviation of all the tasks: duration discrimination using pure tone, pulse train duration discrimination, gap detection threshold, and differential limen of frequency ( - Table $\mathbf{1}$ ). Results revealed lower threshold for all tasks in vocal musicians compared with non-musicians.

Independent $t$-test showed that vocal musicians have a significantly lower threshold compared with non-musicians in duration discrimination using pure tone $(\mathrm{t}=-3.67$; $\mathrm{df}=28$; $p=0.001)$, pulse train duration discrimination $(\mathrm{t}=-4.16$; $\mathrm{df}=28 ; p=0.00)$, gap detection threshold $(\mathrm{t}=-4.06 ; \mathrm{df}$ $=28 ; p=0.00)$, and differential limen of frequency $(\mathrm{t}=$ $-8.15 ; \mathrm{df}=28 ; p=0.00$ ).

-Fig. 1 shows error bar graph of duration discrimination threshold and pulse train duration discrimination threshold for vocal musician and non-musicians. Similarly, - Fig. 2 and - Fig. 3 show error bar graph of gap detection threshold and differential limen of frequency, respectively.

\section{Discussion}

The main aim of the present study is to compare temporal resolution skills in vocal musicians compared with nonmusicians. The present study showed enhanced temporal resolution ability in vocal musicians in comparison to nonmusicians. The better performance of musicians can be attributed to the fact that music exposure helps to develop

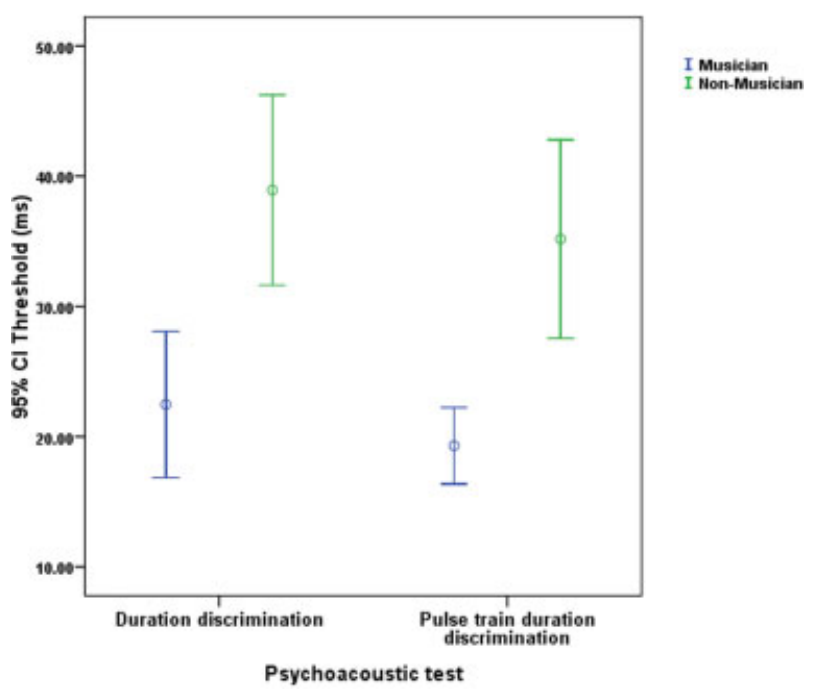

Fig. 1 Error bar graph of duration discrimination threshold and pulse train duration discrimination threshold for vocal musician and nonmusicians. 


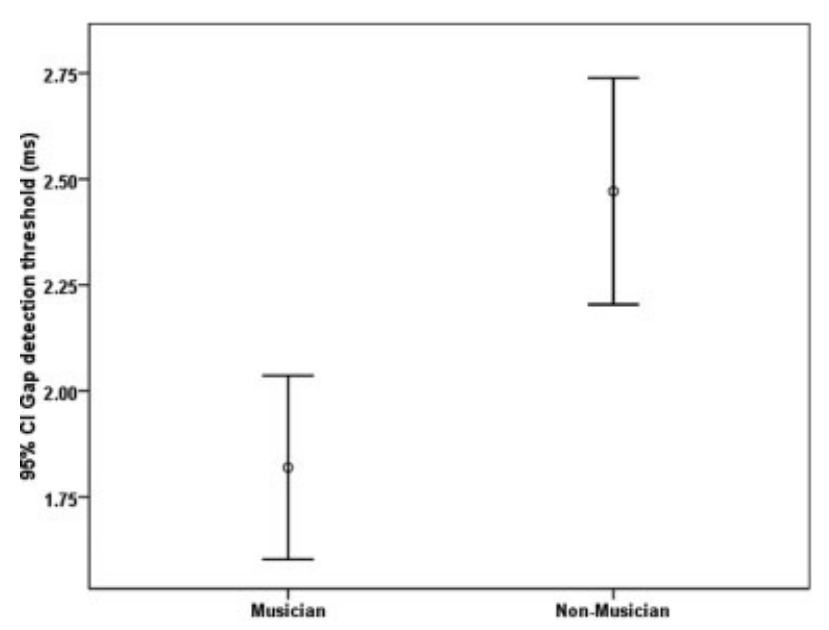

Fig. 2 Error bar graph of gap detection threshold for vocal musician and non-musicians.

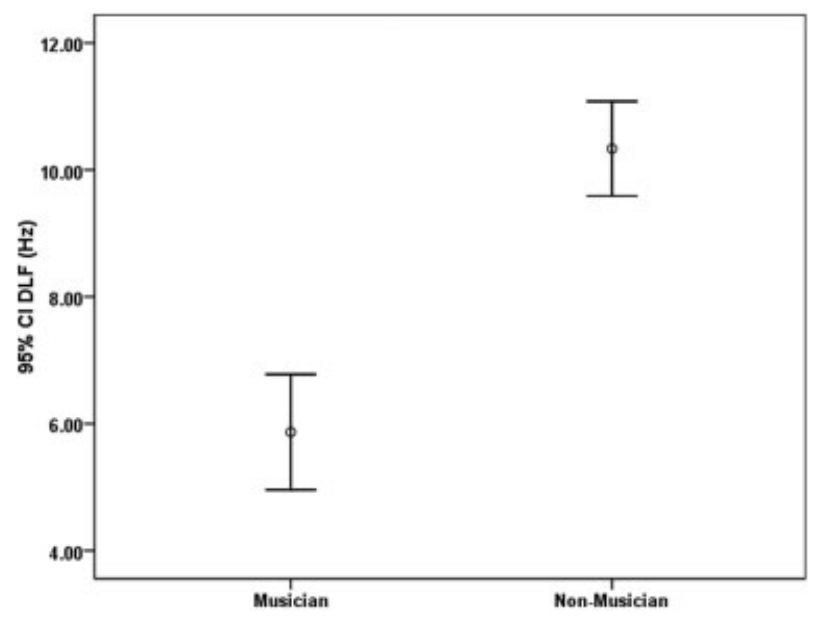

Fig. 3 Error bar graph of differential limen of frequency for vocal musician and non-musicians.

auditory pathways for detecting small change in auditory stimuli. Similarly, the current study also showed better (lower) active discrimination threshold compared with non-musicians, which indicates that musical training and experience has influenced and enhanced active auditory discrimination skills in musicians. Our finding supports those in Fujioka et al and Moreno et al, which reported enhancement of auditory processing with musical training and exposure. ${ }^{16,17}$ The effect of musical training and experience on temporal processing has not yet been studied using combination of tasks (i.e., duration discrimination using pure tones, pulse train duration discrimination, and gap detection threshold). The present study showed that all these tests are equally sensitive in assessing enhanced temporal resolution ability in musicians.

\section{Duration Discrimination using Pure Train and Pulse Train Duration Discrimination}

The current study showed lower threshold among vocal musicians for duration discrimination using pure tone as well as for pulse train duration discrimination, which indicates enhanced temporal resolution ability in musicians compared with non-musicians. This outcome is in consonance with previous literature. ${ }^{18,19}$ Güçlü et al investigated duration discrimination threshold in musicians and nonmusicians and reported that musicians had better duration discrimination threshold compared with non-musicians. ${ }^{18}$ The present study finding is similar with a study done by Sangamanatha et al, which reported lower duration discrimination threshold (better) in children with musical training and adults with musical training, when compared with children without any musical training. ${ }^{19}$

\section{Gap Detection Threshold}

Result showed significantly lower gap detection threshold in vocal musicians compared with non-musicians. Our results are well-supported by other researchers. ${ }^{19-22}$ However, few studies showed no changes due to musical training. ${ }^{23}$ Sangamanatha et al investigated gap detection threshold and reported that mean gap detection thresholds were significantly lower for children with musical training and adults with musical training, when compared with children without any musical training. ${ }^{19}$ Similarly, Mishra, and Panda showed that Carnatic musical training has a significant effect on temporal resolution ability in musicians assessed by gap detection threshold. ${ }^{20}$ The present study's finding is in contrast with the study done by Monteiro et al, which reported no significant difference in gap detection threshold between musicians and non-musicians. ${ }^{23}$

\section{Differential Limen of Frequency}

The current study showed that musicians performed significantly better than non-musicians in differential limen frequency. Threshold of differential limen of frequency for musicians was significantly lower (better) than non-musicians. The finding revealed that musicians have better "active auditory discrimination skill" than non-musicians. Similar, this finding appears in previous literature. ${ }^{24-27}$ Parbery et al compared frequency discrimination in musicians and non-musicians. ${ }^{25}$ They reported that musicians have more fine-grained frequency discrimination. In a similar line, Bidelman and Krishnan measured fundamental (F0) and first formant (F1) frequency difference limens (DLs) in musicians and showed DLs 2 to 4 times better than non-musicians. ${ }^{26}$ In another study, Bidelman et al assessed fundamental frequency discrimination limen between musicians and non-musicians. ${ }^{27}$ They reported trained musicians having significantly better fundamental frequency differential limen when compared with non-musicians. The findings of the current study showed mean DLF for musicians was almost half of the DLF for non-musicians. This indicates that musical training and experience has influenced and enhanced active auditory discrimination skills in musicians.

Thus, musical training can be used to enhance temporal resolution skills and active auditory discrimination skills in the clinical population, such as cases of temporal processing deficit, learning disabilities, Parkinson's disease, schizophrenia, Alzheimer's disease, children with developmental 
language disorder, and children with cochlear implant. ${ }^{28-30}$ Enhancement of temporal resolution ability and active auditory discrimination skills due to musical training in these populations may result in the improvement of speech perception.

\section{Conclusion}

The present study's outcome showed that vocal music training and experience enhances temporal resolution skill and active auditory discrimination ability. These enhancements may be due the fact that more efficient neural network and connections (neuroplasticity) in vocal musicians results in a better threshold in duration discrimination tasks as well as gap detection tasks. Results from the present study support further exploration into the effectiveness of musical training on children with auditory processing disorder. To conclude, musical training is useful in enhancing temporal resolution and active auditory discrimination skills in normal hearing individuals.

\section{References}

1 Musiek FE, Shinn JB, Jirsa R, Bamiou DE, Baran JA, Zaida E. GIN (Gaps-In-Noise) test performance in subjects with confirmed central auditory nervous system involvement. Ear Hear 2005; 26(6):608-618

2 Bellis TJ. Assessment and management of central auditory processing disorders in the educational setting: from science to practice (2nd ed.). New York: Delmar Learning; 2003

3 Downie AL, Jakobson LS, Frisk V, Ushycky I. Auditory temporal processing deficits in children with periventricular brain injury. Brain Lang 2002;80(2):208-225

4 Phillips DP. Central auditory system and central auditory processing disorders: some conceptual issues. Semin Hear 2002;23(2): 251-261

5 Parbery-Clark A, Skoe E, Lam C, Kraus N. Musician enhancement for speech-in-noise. Ear Hear 2009;30(6):653-661

6 Kleim JA, Jones TA. Principles of experience-dependent neural plasticity: implications for rehabilitation after brain damage. J Speech Lang Hear Res 2008;51(1):S225-S239

7 Green CS, Bavelier D. Exercising your brain: a review of human brain plasticity and training-induced learning. Psychol Aging 2008;23(4):692-701

8 Abdul-Kareem IA, Stancak A, Parkes LM, Sluming V. Increased gray matter volume of left pars opercularis in male orchestral musicians correlate positively with years of musical performance. J Magn Reson Imaging 2011;33(1):24-32

9 Amir O, Amir N, Kishon-Rabin L. The effect of superior auditory skills on vocal accuracy. J Acoust Soc Am 2003;113(2):1102-1108

10 Jones JA, Munhall KG. Perceptual calibration of F0 production: evidence from feedback perturbation. J Acoust Soc Am 2000;108(3 Pt 1):1246-1251
11 Mürbe D, Pabst F, Hofmann G, Sundberg J. Effects of a professional solo singer education on auditory and kinesthetic feedback-a longitudinal study of singers' pitch control. J Voice 2004;18(2): 236-241

12 Wong PC, Skoe E, Russo NM, Dees T, Kraus N. Musical experience shapes human brainstem encoding of linguistic pitch patterns. Nat Neurosci 2007; 10(4):420-422

13 Lee KM, Skoe E, Kraus N, Ashley R. Selective subcortical enhancement of musical intervals in musicians. J Neurosci 2009;29(18): 5832-5840

14 Shahin A, Roberts LE, Pantev C, Trainor LJ, Ross B. Modulation of P2 auditory-evoked responses by the spectral complexity of musical sounds. Neuroreport 2005;16(16):1781-1785

15 Carhart R, Jerger J. Preferred method for clinical determination of pure-tone thresholds. J Speech Hear Disord 1959;24(4):330-335

16 Fujioka T, Ross B, Kakigi R, Pantev C, Trainor LJ. One year of musical training affects development of auditory cortical-evoked fields in young children. Brain 2006;129(Pt 10):2593-2608

17 Moreno S, Marques C, Santos A, Santos M, Castro SL, Besson M. Musical training influences linguistic abilities in 8-year-old children: more evidence for brain plasticity. Cereb Cortex 2009;19(3): 712-723

18 Güçlü B, Sevinc E, Canbeyli R. Duration discrimination by musicians and nonmusicians. Psychol Rep 2011;108(3):675-687

19 Sangamanatha AV, Fernandes J, Bhat J, Srivastava M, Prakrithi SU. Temporal resolution in individuals with and without musical training. J Ind Sp Hear Assoc 2012;26(3):27-35

20 Mishra SK, Panda MR. Experience-dependent learning of auditory temporal resolution: evidence from Carnatic-trained musicians. Neuroreport 2014;25(2):134-137

21 Kuman PV, Rana B, Krishna R. Temporal processing in musicians and non-musicians. J Hear Sci 2014;4(3):35-42

22 Mishra SK, Panda MR, Herbert C. Enhanced auditory temporal gap detection in listeners with musical training. J Acoust Soc Am 2014; 136(2):EL173-EL178

23 Monteiro RAM, Nascimento FM, Soares CD, Ferreira MIDC. Temporal Resolution Abilities in Musicians and No Musicians Violinists. Int Arch Otorhinolaryngol 2010;14(3):302-308

24 Kishon-Rabin L, Amir O, Vexler Y, Zaltz Y. Pitch discrimination: are professional musicians better than non-musicians? J Basic Clin Physiol Pharmacol 2001;12(2, Suppl)125-143

25 Parbery-Clark A, Skoe E, Kraus N. Musical experience limits the degradative effects of background noise on the neural processing of sound. J Neurosci 2009;29(45):14100-14107

26 Bidelman GM, Krishnan A. Effects of reverberation on brainstem representation of speech in musicians and non-musicians. Brain Res 2010;1355:112-125

27 Bidelman GM, Hutka S, Moreno S. Tone language speakers and musicians share enhanced perceptual and cognitive abilities for musical pitch: evidence for bidirectionality between the domains of language and music. PLoS ONE 2013;8(4):e60676

28 Overy K. Dyslexia and music: From timing deficits to musical intervention. Ann N Y Acad Sci 2003;999:497-505

29 Walker KM, Hall SE, Klein RM, Phillips DP. Development of perceptual correlates of reading performance. Brain Res 2006; 1124(1):126-141

30 Tallal P, Gaab N. Dynamic auditory processing, musical experience and language development. Trends Neurosci 2006;29(7):382-390 